\title{
A MAP for effective advertising: the metaphoric advertising processing model
}

\author{
Eliza K. Dehay ${ }^{1} \cdot \operatorname{Jan}$ R. Landwehr ${ }^{1}$ (D)
}

Received: 25 April 2017 / Accepted: 3 December 2018 / Published online: 17 January 2018

(C) The Author(s) 2019

\begin{abstract}
Metaphors can trigger attention and surprise, elicit positive feelings when the non-obvious metaphoric meaning is deciphered, and accelerate the understanding of complex or abstract information due to figurative metaphoric associations. Hence, metaphors can satisfy important requirements of marketing communications. Accordingly, in recent decades, an increasing amount of marketing research has examined this concept. The present article provides an overview of this research on metaphors in the advertising literature, outlines the importance of metaphoric advertising for achieving key marketing aims, and identifies crucial research gaps in the current literature. Based on this overview, we integrate theoretical ideas and empirical findings from marketing and (consumer) psychology to develop the Metaphoric Advertising Processing Model (MAP), which offers new insights into the definition, processing, comprehension, and outcomes of metaphoric advertising. We conclude with concrete suggestions and recommendations for future research and describe the practical implications of the model.
\end{abstract}

Keywords Metaphoric advertising $\cdot$ Straightforward advertising $\cdot$ Metaphor $\cdot$ Processing fluency $\cdot$ Schema congruity

A fluffy bear using toilet paper. A car with white clouds and blue sky on its surface. A "big apple" cut into pieces that look like the Sydney Opera House. These examples illustrate how the key benefit of a product or service can be communicated in an advertisement by using metaphors. The first metaphor is used by Charmin to advertise the softness of the brand's toilet paper. The second metaphor is used by Tesla to advertise its zero emission electric cars that do not pollute the air. The third metaphor is used by American Airlines to advertise the direct air connection between New York and Sydney. Such indirect modes of communication in advertising have become increasingly popular in recent decades (e.g., Kim et al. 2012; McQuarrie and Philipps 2005) and are the main topic of the present article.

Jan R. Landwehr

landwehr@wiwi.uni-frankfurt.de

Eliza K. Dehay

epott@wiwi.uni-frankfurt.de

1 Faculty of Economics and Business Administration, Goethe University Frankfurt, Theodor-W.-Adorno Platz 4, 60629 Frankfurt am Main, Germany
More specifically, we focus on metaphors in the domain of visual advertising. Metaphors are rhetorical figures that substitute one thing for another thing, relying on those two things' similarity. Importantly, metaphors carry surplus meaning, which enables them to provide an enriched substitute for a resembling, conceptually similar object (e.g., Levy 1959; McQuarrie and Mick 1996; Moriarty 1987; Scott 1994). Because of their ability to trigger enriched mental associations, metaphors offer promising means for fulfilling communicative goals in marketing practice. Morgan and Reichert (1999, p. 1) apply an enlightening metaphor to emphasize this quality of metaphoric advertising: "metaphors and analogies can be thought of as the ants of advertising. Just as the tiny insect can support many times its own weight, a single metaphor can be worth a hundred words of copy."

Although existing research provides a rich stock of concepts and empirical findings concerning the use of metaphors in marketing - or more specifically, advertising - it nevertheless lacks an overarching conceptual model that explicitly specifies the psychological processes triggered by metaphoric advertising. This article aims to address this gap by providing (a) a literature review of existing insights into the use and importance of metaphors in advertising; (b) a detailed overview of major open research questions in the field of metaphoric advertising; and (c) the development of a new 
conceptual framework of the psychological processing of metaphoric and straightforward advertising (the Metaphoric Advertising Processing Model; MAP) that makes novel predictions for research and practice.

\section{Definition and delimitation of metaphoric advertising}

The idea that many advertising visuals are not straight "reflections of reality" but are based on a complex symbolic system of visual rhetoric that can be used to "write with pictures" has been prominently developed by Scott (1994). One particularly important rhetorical figure in the advertising context is the visual metaphor because it is capable of triggering positive affect and enjoyment (e.g., Gkiouzepas and Hogg 2011), of efficiently transferring large amounts of information (e.g., Morgan and Reichert 1999), and of eliciting important inferences about the advertised product (e.g., Chang and Yen 2013). Moreover, because many metaphors are universally decoded by consumers, Callow and Schiffman (1999) call pictorial metaphors "a kind of visual Esperanto in global marketing". Accordingly, we focus on metaphoric advertising in the present article and contrast the characteristics of this type of advertising with those of its conceptual opposite: straightforward advertising. However, in line with Scott (1994), we note that the distinction between straightforward and metaphoric advertising is a continuum rather than a dichotomy. Nevertheless, we distinguish metaphoric and straightforward advertising by defining idealized prototypes of the endpoints of the continuum to provide a clear-cut conceptual distinction.

\section{Metaphoric advertising}

A metaphor is commonly defined as "an implied comparison between two things of unlike nature that yet have something in common" (Corbett 1990, p. 444). Usually, metaphors are used to make abstract concepts more concrete and comprehensible by explaining the abstract concept in terms of a figurative thing that is open to intuitive experience (e.g., Lakoff and Johnson 1980). Metaphors are literally impossible or false (i.e., in reality there is no direct connection between the two concepts/things) but nevertheless enlightening (Lakoff and Johnson 2003; McQuarrie and Mick 1996, 1999; Toncar and Munch 2001). Accordingly, McQuarrie and Mick argue that metaphors are "incomplete, requiring the reader to fill in a gap" $(1999$, p. 40) to achieve an understanding of metaphoric meaning. When metaphors are used in advertising, this "gap" is commonly characterized by a deviation from the recipients' expectations, for instance, by including unorthodox or unconventional visual or verbal ad elements.

For example, Volvo once released an advertisement that pictures a safety pin bent into the shape of a car (Rossiter and Bellman 2005, p. 135). This depiction of a car is a deviation from expectation because cars are not made of safety pins and safety pins are usually not shaped like a car. However, because safety is a key element of Volvo's brand positioning, substituting the actual product by another object that is predominantly associated with safety signals a key brand characteristic and enables consumers to transfer meaning to the advertised product.

Thus, metaphoric advertising is characterized by replacing one entity (the "target", i.e., a Volvo car) with another conceptually similar entity with surplus meaning (the "source", i.e., a safety pin). The connection between those two entities - source and target - is assumed to be based on an underlying resemblance or conceptual similarity (McQuarrie and Mick 1996, 1999). Importantly, the analogy between source and target does not stem from incidentally resembling features of both, but from shared feature structures or relations that are likewise inherent to the source and the target. To comprehend a metaphoric advertisement, consumers must detect the predominant common structure between source and target, apply knowledge about the source and target to determine whether and how they match, and infer which interpretation is most relevant in a given context (Gentner et al. 2001). Importantly, metaphoric advertising is neither precise nor obvious because the surplus meaning is hidden, as described above (see also Lakoff and Johnson 2003). Accordingly, metaphoric advertising is not only complex and sophisticated in terms of meaning decoding but is also an indirect tool of marketing communications (Levy 1959; Phillips 1997; Scott 1994; Toncar and Munch 2001).

\section{Straightforward advertising}

Straightforward advertising is an advertising type that is free of metaphoric or other meaning-loaded visual or verbal ad elements. This type of advertising merely identifies and denotes product or brand information or describes the usage of a product (Moriarty 1987). By containing explicit claims and factual information, straightforward advertising informs consumers in a direct, literal, or straight way (Moriarty 1987; Rossiter and Percy 1997; Toncar and Munch 2001). Note that what we denote as straightforward advertising has also been referred to as literal (Gentner et al. 2001; Moriarty 1987), representational (Dondis 1973), or straight (Rossiter and Percy 1997, p. 287) advertising.

We suggest that straightforward advertising does not contain hidden surplus meaning because the direct or explicit ad elements only refer to themselves. Although straightforward advertising may elicit multiple thoughts, interpretations, and associations (Lagerwerf and Meijers 2008), consumers are not required to draw their own inferences or to detect hidden meaning to understand the advertising message. This assumption is in line with the finding that straightforward 
advertising can be taken literally (Toncar and Munch 2001). Because it is literally correct (direct communication, no hidden meaning, etc.) and its degree of deviation from reality is low, straightforward advertising requires less complex meaning decoding processes than metaphoric advertising (McQuarrie and Mick 1996).

To conclude this section, Table 1 summarizes the most important defining characteristics of metaphoric and straightforward advertising with respect to the mode of meaning transfer, the degree of communicative complexity, and the degree of deviation from consumers' expectations. Next, we turn to the importance of metaphoric advertising for creating effective advertisements.

\section{The link between metaphoric advertising and advertising effectiveness}

Common models of advertising effectiveness propose and show that attitude toward the ad is an important determinant of consumers' behavioral intentions and that its effect is transferred simultaneously by positive brand attitudes/evaluations and positive product/brand cognitions (e.g., Homer 1990; MacKenzie et al. 1986; Mitchell and Olson 1981; for a meta-analysis, see Brown and Stayman 1992). The previously described key characteristics of metaphoric advertising (see Table 1) suggest that this type of advertising should be particularly effective in influencing these two process variables for at least three reasons. First, achieving an understanding of the metaphoric link between source and target is like solving a riddle, which triggers positive affect and hence positive attitudes toward the ad and positive brand evaluations (e.g., Mohanty and Ratneshwar 2015). Second, metaphors are perceived as creative rhetorical figures that stimulate consumers' imagination, which should also transfer to positive attitudes toward the ad and positive brand evaluations (e.g., Zaltman and Coulter 1995). Third, because metaphors enhance consumers' understanding of abstract concepts, metaphoric advertising facilitates the transfer of information and beliefs about product attributes and is hence able to trigger positive product/brand cognitions (e.g., McQuarrie and Mick 1999; McQuarrie and Philipps 2005).

In line with this latter point, Burgers et al. (2015) showed that metaphoric advertising provides a suitable tool for making abstract benefits more concrete and tangible, which in turn increases the persuasiveness of advertising for such products/services. Thus, metaphoric advertising could help consumers to intuitively experience abstract product/service features that would otherwise remain difficult to grasp. Moreover, it has been shown that metaphoric advertising is an effective tool to transfer symbolic meaning to brands, create and manage brand personality (Ang and Lim 2006), and position brands in the marketplace (Alden et al. 1999; Randazzo 2006). In addition to the transfer of explicit brand personality perceptions, Delbaere et al. (2011) showed that when a product in an ad metaphorically engages in some type of human behavior, the brand is anthropomorphized, which elicits feelings of connectedness and increases brand liking. Thus, metaphoric advertising seems to be capable of capitalizing on the positive effects of brand anthropomorphism reported in the literature (e.g., Aggarwal and McGill 2007; Landwehr et al. 2011).

To further exemplify how metaphoric advertising can increase advertising effectiveness, one can also refer to the traditional communication model by Shannon and Weaver (1949), which explains communication as a process in which a sender (i.e., a brand) sends a signal (i.e., an advertising message) to a receiver (i.e., a consumer). According to the summarized research findings, metaphoric advertising is a communicative signal that is able to efficiently transfer information and positive feelings from the sender to the receiver. Hence, metaphoric advertising constructs an important bridge between brands and consumers (see also Hawkins 1973) and thus fulfills a fundamental aim of marketing communications. To dig deeper into the mechanisms that make metaphoric advertising a promising instrument of effective advertising, we will turn to key aspects of consumers' mental processing of metaphoric advertising in the next section.

Table 1 The most important defining characteristics of metaphoric versus straightforward advertising

\begin{tabular}{|c|c|c|}
\hline & Metaphoric advertising & Straightforward advertising \\
\hline Transfer of meaning & $\begin{array}{l}\text { - substitution of one thing by another thing } \\
\text { (McQuarrie and Mick 1996). } \\
\text { - not to be understood literally (Toncar and Munch 2001). } \\
\text { - carries additional hidden meaning } \\
\text { (Phillips 1997; Toncar and Munch 2001). }\end{array}$ & $\begin{array}{l}\text { - denotes information in a direct way (Moriarty 1987; } \\
\text { Rossiter and Percy 1997). } \\
\text { - contains explicit claims (Toncar and Munch 2001). } \\
\text { - does not contain hidden meaning (Toncar and Munch 2001). }\end{array}$ \\
\hline Degree of complexity & $\begin{array}{l}\text { - complex, sophisticated, rhetorical, figurative way of } \\
\text { communication (Scott 1994). } \\
\text { - indirect transfer of information (Toncar and Munch 2001). }\end{array}$ & $\begin{array}{l}\text { - less complex in terms of meaning-decoding than metaphoric } \\
\text { ads (McQuarrie and Mick 1996) and literally correct } \\
\text { (Toncar and Munch 2001). }\end{array}$ \\
\hline Degree of deviation & • deviates from expectation (McQuarrie and Mick 1996). & - does not deviate from expectation. \\
\hline
\end{tabular}




\section{Key insights and research gaps concerning metaphoric advertising}

Based on the general review of definitional characteristics and the importance of metaphoric advertising provided in the previous sections, we now turn to key insights and remaining research gaps concerning the processing and evaluation of metaphoric advertisements. This overview constitutes the foundation for the novel processing model of metaphoric advertising, which we will develop in the subsequent section. To this end, Table 2 provides an overview of five selected major objects of knowledge in the current literature on metaphoric advertising. For each of these five objects, we summarize the key insights of the current literature and identify the remaining research gaps.

\section{Complexity of metaphoric advertising}

The current literature offers two comprehensive typologies of metaphoric advertising that can be used to determine the complexity of the employed metaphors based on the visual structure and the connection/comparison implied by the metaphor (Phillips and McQuarrie 2004; Gkiouzepas and Hogg 2011). These typologies are very helpful for structuring the creative space that metaphors offer for the design of advertisements and for enabling a systematic examination of the advertisement's visual appearance. In particular, they indicate metaphoric complexity as an essential conceptual dimension to understand the effects of metaphoric advertising. From a psychological processing perspective, the complexity of a metaphor can be conceptualized as a processing affordance with higher levels of complexity requiring higher levels of processing effort. This perspective gives rise to two important research questions. First, which psychological processes are triggered when higher versus lower levels of metaphoric complexity are encountered? Second, are there any other creative aspects of the advertisement that concurrently increase the perceived complexity of an ad?

\section{Processing of metaphoric advertising}

When considering the second object of knowledge (see Table 2), there is consensus in the current literature that metaphoric advertising elicits higher levels of cognitive elaboration than straightforward advertising (e.g., Gkiouzepas and Hogg 2011; Lagerwerf and Meijers 2008; DeRosia 2008; Kim et al. 2012; McQuarrie and Mick 1999). Moreover, several authors assume that metaphors are cognitively demanding and thus, processed on a deep semantic level (e.g., Fox et al. 2015; Mohanty and Ratneshwar 2015; Scott 1994). These observations raise the question of why metaphoric advertising triggers higher levels of cognitive elaboration. More specifically, what psychological processes cause people to invest higher amounts of cognitive effort?

Another as-yet unresolved question is whether metaphoric ad elements are easy or difficult to process. On the one hand, metaphors ease decision-making and facilitate processing because they make abstract ad concepts more concrete and thus, more understandable (Cian et al. 2015; Gentner et al. 2001; Levy 1959). On the other hand, to understand metaphors in the intended manner, the recipient of a message must draw inferences (Toncar and Munch 2001), activate knowledge (e.g., cultural knowledge), or apply strategies such as interpretation (e.g., Phillips 1997). These processes, however, burden the recipient's cognitive processing capacities.

\section{Affective/evaluative consequences of metaphoric advertising}

The affective and evaluative consequences of processing metaphoric advertising critically depend on how the processing proceeds. If consumers correctly interpret a metaphor, they feel enlightened by their (new) conclusions (McQuarrie and Mick 1999; Phillips 1997). To achieve this, consumers must activate product, situational, or personalized knowledge and engage in their own interpretations and inferences (e.g., Mick 1992). The successful processing of metaphors thereby promotes feelings of reward and pleasure and, thus, positive attitudes toward the ad (e.g., Gkiouzepas and Hogg 2011; Mohanty and Ratneshwar 2015; McQuarrie and Mick 1996, 1999). Accordingly, van Mulken et al. (2010, 2014) find clear evidence for an inverted $u$-shaped relationship between metaphoric complexity and the appreciation of an ad. That is, if it is too easy or too difficult to understand a metaphoric ad, appreciation is reduced. In contrast, if an advertiser meets the "sweet spot" of optimal metaphoric complexity, consumers experience pleasure and reward when solving the "riddle" posed by the metaphor. Another finding that corresponds with this line of research shows that straightforward advertising claims can be more effective if consumers are neither willing nor able to engage in effortful or deep processing, which is both required to fully understand metaphoric advertising (Toncar and Munch 2001).

These insights lead to two major research opportunities. First, there has been no systematic theoretical analysis of the involved mechanisms that produce the inverted $u$-shape between metaphoric complexity and ad appreciation that would offer a parsimonious explanation for the observed effects. Second, without a proper theoretical understanding, it is difficult to specify the optimal level of metaphoric complexity for achieving positive evaluations. Thus, specifying when exactly metaphoric advertising leads to more favorable evaluations is a question that requires an advanced process understanding and further research. 


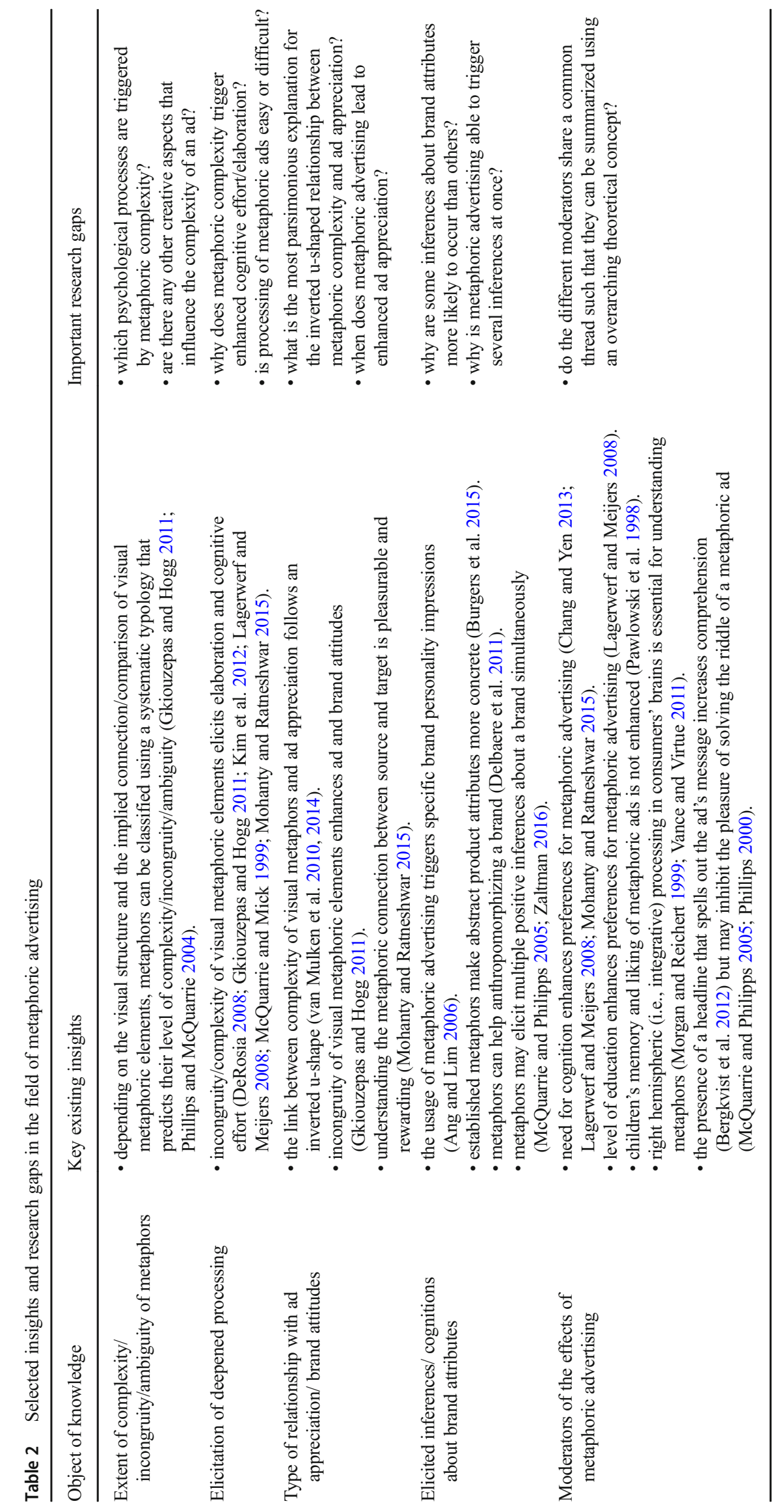




\section{Cognitive consequences of metaphoric advertising}

Metaphoric advertising has been shown to trigger a number of positive cognitive consequences. First, the usage of metaphors increases the likelihood that the ad will be retained in memory (Phillips and McQuarrie 2004; Rossiter and Percy 1997). Second, metaphors are a means to generate new conclusions by facilitating cognitive enrichment and imaginative thinking (Zaltman 2016), which may contribute to the ability of metaphors to trigger multiple positive inferences about a brand simultaneously (McQuarrie and Philipps 2005). Third, metaphoric advertising makes abstract product attributes more concrete and hence tangible for consumers (Burgers et al. 2015). Fourth, Delbaere et al. (2011) showed that when a product in an ad metaphorically engages in some type of human behavior, the brand is anthropomorphized, which increases brand liking and more positive attributions of brand personality. Fifth, metaphoric ads are less likely to provoke consumers' resistance to the ad claim because it is more difficult for consumers to challenge and question hidden ad meaning than straightforward claims (Toncar and Munch 2001).

In this respect, it is important to note that direct claims can be more effective in high-involvement choice situations because in such cases, highly motivated consumers seek efficient, factual, and straight information (Rossiter and Percy 1997; Toncar and Munch 2001). Furthermore, when consumers strive to satisfy basic needs (such as hunger), a straightforward ad that contains an explicit picture of the object that satisfies the need (e.g., food) may be most successful (Rossiter and Percy 1997).

A final important finding in the context of brand personality creation is that only some brand personality traits can be effectively delivered by metaphoric advertising. In particular, metaphoric advertising is most effective in increasing perceptions of sophistication and excitement, whereas straightforward advertising is most effective for sincere and competent brands (Ang and Lim 2006).

Based on the reported findings, the following major research questions emerge. The first question directly connects to the findings of Ang and Lim (2006) and asks why some types of brand personality inferences are more likely to occur for metaphoric advertisements than others. The second question is related to the finding that metaphoric ads trigger a multitude of cognitive inferences, which requires a profound process explanation.

\section{Moderators of the effects of metaphoric advertising}

The positive effect of metaphoric advertising on the abovediscussed evaluative and cognitive consequences has been shown to be conditional on a number of moderating variables. Several studies have examined variables connected to cognitive processing capability and have provided evidence that metaphoric advertising is more effective for consumers with a high need for cognition (Chang and Yen 2013; Lagerwerf and Meijers 2008; Mohanty and Ratneshwar 2015), with higher education (Lagerwerf and Meijers 2008), and with higher cognitive maturity (i.e., metaphoric advertising seems to be less beneficial for children; Pawlowski et al. 1998).

Furthermore, the type of processing activated by a metaphoric ad (i.e., integrative vs. analytical) is also known to moderate the effectiveness of the ad such that consumers who process the ad in an integrative manner (i.e., predominant processing in the right hemisphere of the brain) show greater understanding and appreciation of the ad (Morgan and Reichert 1999; Vance and Virtue 2011).

Finally, several researchers have examined the effects of the presence and type of an explanatory headline that spells out the message of the ad on advertising effectiveness (Bergkvist et al. 2012; McQuarrie and Philipps 2005; Phillips 2000). The key idea is that an explanatory headline supports ad recipients' understanding of the riddle posed by the metaphoric ad, which should be transferred to increased appreciation of the ad. However, the evidence is mixed with respect to the optimal extent of explanation offered by the headline. Some researchers suggest that a headline that fully explains the ad is superior (Bergkvist et al. 2012), while others suggest that an incomplete headline that still leaves some room for self-detection of the ad's meaning is superior (McQuarrie and Philipps 2005; Phillips 2000).

The key question regarding the three above-described types of moderators is whether they could be theoretically integrated and understood using an overarching theoretical concept. Such a generalized understanding would help specify the conditions under which metaphoric advertising can be expected to be particularly effective and when it is not likely to work.

\section{Concluding remarks concerning the major research gaps}

Table 2 summarizes the five key areas of research in the domain of metaphoric advertising and presents the key insights provided by the current literature. It also identifies nine important open research questions (derived from the literature review) that call for a better understanding of the psychological processes triggered by metaphoric advertising, the determinants and consequences of metaphoric complexity, the type and amount of cognitive inferences triggered by metaphoric advertising, and the potential moderating conditions of the observed effects of metaphoric advertising.

The key aim of the present article is to offer a novel theoretical perspective on these research gaps that could inspire and enrich further research on metaphoric advertising. In particular, we suggest that the processing fluency framework (e.g., Graf and Landwehr 2015; Reber et al. 2004) offers a very promising and powerful approach to increase our 
understanding of when, why, and how metaphoric advertising is likely to be an effective advertising strategy. Thus far, the processing fluency framework has never been applied to metaphoric advertising, which offers many novel research opportunities. In what follows, we will present our Metaphoric Advertising Processing Model (MAP) to fill this gap and to provide a comprehensive framework for future research on metaphoric advertising.

\section{The metaphoric advertising processing model (MAP)}

In this section, we develop the main ideas and propositions underlying our integrative theoretical model of the processing of metaphoric (versus straightforward) advertising. The model addresses the research gaps mentioned above by merging ideas from marketing/advertising research and cognitive psychology. The core idea of our model is inspired by the Remote Conveyer Model, which is a conclusive management model on how to generate creative ideas for marketing communications and how to improve consumers' brand benefit learning (Rossiter and Bellman 2005; Rossiter and Percy 1997). The Remote Conveyer Model suggests that the implementation of a conveyor increases the effectiveness of advertising. Conveyors are eye-catching stimuli, which have the objective of attracting attention. Because they are remote from the advertised product or service (i.e., they are unlikely to co-occur in the real world), conveyors create curiosity, which activates consumers to search for the key product/ service benefit. If consumers succeed in doing so, they understand the ad and perceive a "quick mental reward" (Rossiter and Bellman 2005, p. 132). As opposed to straightforward ads, the authors describe conveyor ads as making purposefully indirect claims. They describe conveyors as metaphors that dramatize the key benefits of the advertised product or service by linking it to "another object that has that benefit even more strongly" (p. 135).

According to Rossiter (2008, p. 143) "a major contribution of the Remote Conveyor Model is the identification of the properties of an effective conveyor" that elicits increased attention, curiosity, and an active search for the match between conveyor and product. Thus, the model is highly helpful for creating effective advertisement stimuli and for predicting important advertising outcome variables. However, the aims and scope of the model do not cover the concrete psychological processing characteristics that trigger attention, curiosity, and elaborated processing as a result of perceiving metaphoric advertising.

To close this gap, we present a model that focuses on the psychological processes underlying the effects described by the Remote Conveyer Model. Our novel model integrates insights from schema congruity theory to define the characteristics of metaphoric versus straightforward advertising from a consumer's perspective. It also integrates insights from processing fluency and structure-mapping theory to advance novel propositions involving the processing, comprehension, and downstream consequences of metaphoric advertising. Figure 1 summarizes this Metaphoric Advertising Processing Model (MAP).

\section{Congruity of visual ad elements}

The MAP is based on the idea that the interplay of different visual ad elements defines whether an advertisement can be classified as metaphoric or straightforward. In particular, when a consumer perceives an advertisement, s/he will instantaneously form an impression of whether the visual elements of the ad are high or low in congruity. Congruity is generally defined as a correspondence between the schematic expectations derived from experience and observed evidence (e.g., Mandler 1982). The MAP suggests that a low congruity between visual ad elements is a necessary precondition for an advertisement to contain metaphoric meaning. Accordingly, the very first impression of a metaphoric ad is unusual and differs from the expectation of the message recipient. In contrast, the MAP denotes advertising as straightforward when the visual ad elements are perceived as congruent and fitting well together. In particular, one key objective of straightforward advertising is to illustrate a product or product features by depicting it in a direct and explicit ad surrounding that is logical and exists in the real world. Thus, no riddle must be solved and no hidden meaning must be detected in straightforward advertisements.

One example from a real campaign to distinguish metaphoric and straightforward advertising is a Red Bull campaign in which wings are added to the product, a can of Red Bull energy drink (see Fig. 2 for an application of the MAP to this exemplary Red Bull advertisement). In this example, the visual ad elements do not correspond: cans do not have wings. The message recipient does not expect to see cans with wings because this combination of ad elements does not correspond to reality, thus the metaphor carries additional meaning. By connecting the Red Bull energy drink to the wings of a bird, the advertisement emphasizes the energizing and uplifting effect of the soft drink on the consumer: Red Bull will lift you up the way that wings uplift a bird or a plane. This secondary meaning is delivered by the presence of the initially incongruent elements of the wings and the Red Bull can. A metaphor enables the message recipient to understand underlying abstract concepts such as "energy" that otherwise are difficult to communicate. In this sense, metaphors can be used as concrete depictions (e.g., tangible wings) of underlying abstract concepts (e.g., energy), which transfer meaning from one ad element (wings) to another (can) by pointing to underlying semantic relations (the energizing 
Fig. 1 The Metaphoric Advertising Processing Model (MAP)

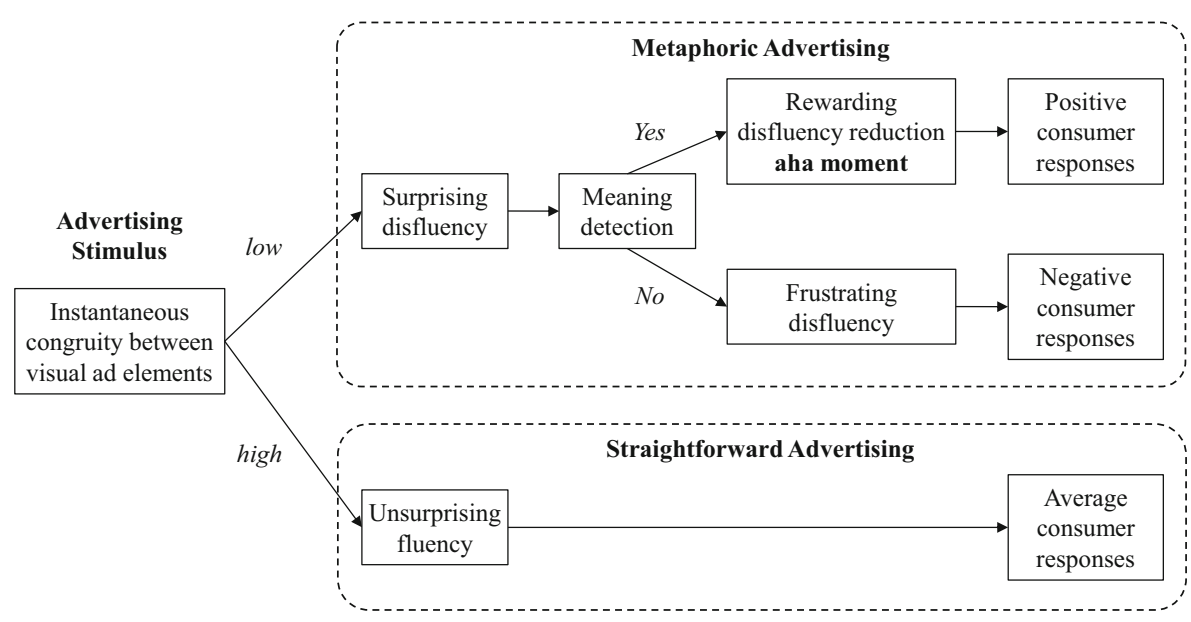

effect of an uplift) that are characteristic of both. Thus, they can be described as "semantic bridges" between abstract meaning and concrete products/services.

In contrast, a Red Bull ad that either shows a person consuming the energy drink or depicts the can in front of a party background is straightforward advertising because both situations fit consumers' expectations about the consumption of soft drinks. Thus, the ad elements (can, consumer, consumption situation) are congruent and the ad communicates in a highly illustrative manner, makes direct claims, and does not deviate from expectations or reality. The underlying messages of metaphoric (e.g., Red Bull lifts you up) and straightforward (e.g., Red Bull is a party drink) advertisements exemplify our reasoning and demonstrate that unlike straightforward advertising, metaphoric advertising contains additional hidden meaning.

We consider schema congruity a suitable theoretical approach to explain the relationships between ad elements. However, our understanding of congruity differs from that proposed by schema congruity theory in that we investigate congruity on a purely pictorial level. Classical schema congruity theory (e.g., Meyers-Levy and Tybout 1989) considers the congruity between a product and a product category schema. In contrast, our concept of congruity refers to the mere congruity between visual ad elements. That is, we focus only on the congruity between the stylistic elements of an advertisement and the underlying meaning they transfer. In the case of the described Red Bull ads, we do not suggest that the congruity between Red Bull and the "energy schema" is higher or lower than the congruity between Red Bull and the "party schema", but that the congruity between wings and soft-drink cans is lower than the congruity between a party and soft-drink cans.

In conclusion, metaphoric advertising is a type of marketing communication in which visual ad elements are initially incongruent, but the incongruity can be resolved through the conceptual relationship between the visual elements (see next paragraph). Importantly, metaphoric advertising carries surplus meaning and denotes something other than itself, thereby demonstrating that it is an indirect form of communication (see also Levy 1959). The meaning of metaphoric advertising unfolds through the interplay between the ad elements and consumers' knowledge about the product/brand. In contrast, straightforward advertising does not produce additional meaning through the interplay of different ad elements, although it might elicit multiple thoughts and associations. Thus, the core difference between both ad types is that metaphoric ads are initially incongruent because they contain hidden meanings, whereas straightforward ads do not contain hidden meanings because of their instantaneous congruency. As a result of these defining characteristics, metaphoric advertising is a more complex and figurative means of communication than straightforward advertising.

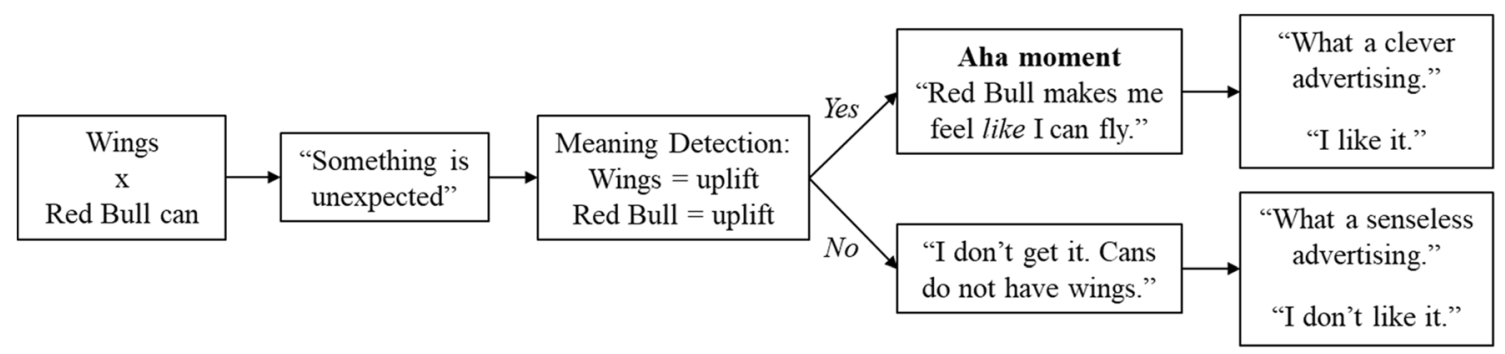

Fig. 2 Metaphoric advertising processing of a Red Bull advertisement 


\section{Processing fluency and the aha moment}

Extending existing research on ad processing and comprehension, this paragraph describes how the MAP applies central ideas of processing fluency theory to explain the processing of metaphoric and straightforward advertising. Fluency theory predicts that certain perceptual and conceptual characteristics of stimuli generally influence the ease or difficulty with which the stimuli are processed and that fluent processing is an inherently positive experience (e.g., Reber et al. 2004). Recent studies, however, show that some extent of disfluency may also result in interest (Graf and Landwehr 2017), positive product evaluations (e.g., perceived innovativeness and subsequent liking, Cho and Schwarz 2006), or increased purchase intentions (Motyka et al. 2016). Based on a dual process perspective on fluency effects (Graf and Landwehr 2015), we will integrate such positive effects of disfluency into the MAP as outlined below.

In terms of the processing difficulty of metaphoric ads, some researchers studying marketplace symbolism have assumed that symbols and metaphors are easy to process, but they have not provided a detailed explanation or empirical evidence to support this assumption (e.g., Levy 1959). Others have assumed that metaphoric advertising is processed less fluently (Fox et al. 2015). We refine both perspectives by proposing that metaphoric ads are initially more difficult to process than straightforward ads and that further processing may dynamically change the fluency experience. Figure 1 provides a schematic depiction of consumers' core processing steps when confronted with an ad and how the experienced fluency levels at each step determine the final evaluation of the ad. Crucially, the MAP proposes that three distinct consumer responses can result from the specific sequence of processing steps and their fluency.

Starting with the pathway leading to the upper outcome of the MAP, the initial feeling of disfluency occurs because of the metaphoric advertisement's deviation from expectations or reality (i.e., instantaneous perception of incongruity). If the message recipient detects the underlying ad meaning, s/he experiences a so-called aha moment. Aha moments are characterized by sudden insights into the solution of a problem, reduced feelings of disfluency, and the induction of positive affect and perceptions of truth and confidence (Graf and Landwehr 2015; Muth and Carbon 2013; Topolinski and Reber 2010). Indeed, at the moment of stimulus processing, such sudden changes in fluency exert a greater impact on stimulus judgments than does the absolute level of fluency (Wänke and Hansen 2015). Hence, when consumers perceive a low level of congruity in the first step and can detect meaning in the second step, positive consumer responses are likely to occur (see Fig. 1).

Although previous studies have reported positive consumer responses to metaphoric advertising (e.g., Ang and Lim 2006;
Delbaere et al. 2011; Randazzo 2006), successful processing and the associated positive responses do not always occur. Consumers do not necessarily detect the hidden meaning of an ad message because of a lack of semantic or conventional understanding. For instance, miscommunication occurs if consumers perceive a communicated brand personality in an unintended manner (Aguirre-Rodriguez 2014). The pathway leading to the middle outcome in Fig. 1 represents these possible negative effects of metaphoric advertising. If consumers cannot detect the underlying ad meaning, the initial feelings of disfluency remain and negative consumer responses result (e.g., a lack of ad comprehension or reduced ad and brand preferences). In accordance with the Pleasure-Interest Model of Aesthetic Liking (Graf and Landwehr 2015), we propose that the absence of disfluency reduction (i.e., failing to resolve the meaning implied by an ad) triggers frustrating confusion, which is negatively valenced.

Finally, we predict that consumers can immediately process straightforward advertising fluently because of the high level of instantaneous congruity. However, the experienced fluency is unsurprising because consumers expect ad elements to be congruent. Consequently, straightforward advertising produces "average consumer responses": it neither benefits from the illuminating insights of meaning detection nor suffers from the negative outcomes of failed meaning detection shown in Fig. 1. The finding that surprising experiences produce more intense outcomes than do expected experiences (Graf and Landwehr 2017; Wänke and Hansen 2015) reinforces our predictions regarding the outcomes of the two metaphoric pathways compared with the straightforward pathway. Although straightforward advertising facilitates processing, which has been shown to produce positive outcomes, this experience is nevertheless unsurprising and therefore less intense (see Pezzo (2003) for a similar assumption about the importance of surprise for moderating the intensity of hindsight bias).

Our processing fluency perspective on metaphoric advertising is complemented by ideas and findings related to schema congruity theory. More specifically, Meyers-Levy and Tybout (1989) detected an inverted u-shaped relationship between congruity (between a product and a product category schema) and product evaluations such that moderate incongruity produces the most desirable consumer responses. They explain this result by positing that resolving incongruity is rewarding and therefore triggers positive affect, whereas high congruity (i.e., nothing to resolve) and strong incongruity (i.e., not resolvable) trigger less positive evaluations. Applied to the current advertising context, ads that evoke moderate incongruity between different ad elements should be preferred over ads that evoke high levels of congruity or incongruity (van Mulken et al. 2010, 2014).

The pathways leading to the three distinct outcomes of the MAP readily accommodate these ideas. First, metaphoric ads 
are moderately incongruent if initial feelings of disfluency can be reduced by detecting the underlying meaning of the ad message (pathway leading to the upper outcome). Hence, we predict that "resolved" metaphoric ads produce the most positive consumer responses (i.e., rewarding disfluency reduction leads to interest). Second, "unresolved" metaphoric ads produce the worst consumer responses (e.g., frustrating disfluency leads to confusion) because the initial feelings of disfluency, which stem from the incongruity between the ad elements, cannot be reduced (pathway leading to the middle outcome). Finally, the pathway leading to the bottommost outcome represents congruent straightforward ads, which provoke positive but-as Mandler (1982, p. 22) frames it"cold" consumer responses (e.g., boredom) resulting from unsurprisingly fluent processing.

Researchers in other fields have similarly described these three outcomes. For instance, the Pleasure-Interest-Model of Aesthetic Liking (Graf and Landwehr 2015) posits that aesthetic stimuli, whose processing is more or less fluent than expected, trigger an experience of fluency discrepancy. Whereas a positive discrepancy results in feelings of pleasure, negative fluency discrepancy may trigger interest, if there is motivation to further process the stimulus and an ability to reduce disfluency. Otherwise, boredom or confusion may result. Berlyne (1960) makes similar predictions based on the arousal potential of the stimulus being evaluated. Thus, it seems desirable for marketing managers to create advertisements with a moderate (i.e., resolvable) level of incongruity.

\section{How to detect the underlying meaning of metaphoric ads}

In the previous section, we described three potential outcomes of metaphoric and straightforward ad processing, thereby explaining that metaphoric advertising can either be resolved or remains unresolved. This notion requires further explanation. To understand the relationship between the incongruent ad elements, the consumer must detect how they are conceptually or semantically similar. If consumers detect a conceptual connection, they can resolve the hidden ad meaning and experience the aha moment of understanding. Otherwise, processing remains disfluent. Thus, meaning detection is a moderating process that is crucial for consumers' subsequent processing and ad responses.

More precisely, consumers must detect resembling feature structures, which are prevalent in the source of surplus meaning (i.e., the incongruent ad element), and transfer them to the target (i.e., the brand, product, or service). Gentner (1983) and Gibbs (2000) suggest that not specific features of source and target are critical for this associative connection, but the relational structures in the source must match the relational structures in the target. In other words, they must have similar meaning structures, not just similar features. Although two objects may have many features in common, they might not be metaphorically associated because their shared features are not relevant (Gentner et al. 2001).

In the Red Bull example, the wings and the can might have many similar features (e.g., size or color) that nevertheless are irrelevant to their shared association of energy. However, the relational structure of wings and the energy drink is crucial, namely, in that both trigger an uplift, which in turn releases energy. This assumption of structure-mapping theory (Gentner 1983) is empirically supported by the finding that relational processing (encoding information holistically) rather than item-wise processing (encoding chunks of information individually) helps consumers understand incongruent metaphoric advertising messages (Mohanty and Ratneshwar 2015).

Regarding the Red Bull advertising, the metaphor deviates from reality, and is therefore incongruent with consumers' expectations (i.e., Red Bull cannot fly, nor will the consumer fly after consuming the energy drink). However, the two ad elements are connected by an underlying abstract commonality, meaning they share certain feature structures (i.e., wings lift up birds and Red Bull lifts up consumers by releasing energy). This semantic relatedness of the two concepts (i.e., the equivalence between the two uplifts) enables the message recipient to understand the intended ad meaning. Figure 2 illustrates our predictions for this metaphoric Red Bull ad.

In terms of processing effort and capacity invested by consumers, the MAP adopts a dual process perspective (cf. Graf and Landwehr 2015). We assume that the instantaneous perception of (in)congruity and the initial feelings of disfluency or fluency derive automatically and are the result of incidental, low-effort ad processing. However, the detection of underlying ad meaning in metaphoric ads requires that consumers engage in effortful cognitive processing in a second step. Thus, consumers can only resolve disfluency and experience a positive aha insight if they engage in effortful cognitive processing; otherwise, they fail to resolve disfluency and are frustrated. In contrast, the processing of ordinary straightforward ads does not necessarily require cognitive effort to understand the ad's message (ads for technologically sophisticated products might be an exception such that expert knowledge and cognitive effort are required to understand the content of the ad). However, should consumers become motivated to engage in effortful cognitive processing of ordinary straightforward ads, they can become bored by the fact that no hidden meaning can be discovered and that the ad does not challenge their processing efforts.

\section{Conclusions and suggestions for future research implied by the MAP}

In sum, the MAP argues that metaphoric advertising is characterized by the instantaneous incongruity of visual ad 
elements. The consumer notes that the advertising deviates from reality or from what $\mathrm{s} /$ he expects. This feeling of incongruity manifests in disfluent ad processing. If consumers detect the hidden conceptual relationship between ad elements, they experience a sudden illumination (aha moment), which increases processing fluency and positive responses to the ad. However, if they do not detect the underlying ad meaning, processing remains disfluent and consumers react negatively toward the metaphoric ad. Furthermore, the MAP suggests that straightforward advertising is characterized by a high congruence between ad elements, which results in unsurprisingly fluent processing and weak consumer responses. According to our model and in line with former empirical and theoretical findings (e.g., Gkiouzepas and Hogg 2011), we argue that resolvable metaphoric advertising is generally preferred over straightforward advertising.

In terms of future research on metaphoric advertising, the MAP offers a conceptual framework for systematically examining the important research gaps identified in the literature review and summarized in the outer-right column of Table 2. Specifically, it suggests that the effects of metaphoric advertising can be traced to the experience of processing fluency, which suggests that established insights provided by the literature on processing fluency could be transferred to the study of metaphoric advertising (for a review of common fluency phenomena, see Graf et al. 2018). To demonstrate these research opportunities, we highlight how the research gaps within the five domains of research summarized in Table 2 could be approached from a processing fluency perspective.

First, analyzing the complexity of metaphoric advertisements could be enriched by considering processing fluency as suggested by the MAP because the fluency literature suggests a number of stimulus characteristics that influence processing ease over and above metaphoric complexity such as visual typicality, visual complexity, visual contrast/clarity, and visual symmetry (e.g., Reber et al. 2004). Hence, it would be very interesting to examine how these essential visual variables present in any visual ad interact with the determinants of metaphoric complexity described by Phillips and McQuarrie (2004) and by Gkiouzepas and Hogg (2011). Moreover, considering metaphoric complexity from a processing fluency perspective may help refining the typologies of metaphorical visual structures as proposed by Phillips and McQuarrie (2004) and by Gkiouzepas and Hogg (2011). Such a refinement would be based on the idea that the fit between conceptual elements is an important determinant of processing fluency (Graf et al. 2018).

Second, concerning deepened processing elicited by metaphoric advertising, the fluency perspective suggested by the MAP makes the testable prediction that initial disfluency is a necessary trigger of deepened processing. This proposition is based on the finding that the mere experience of disfluent processing elicits controlled and effortful cognitive processing because it signals that the situation offers a potential for cognitive enrichment and cannot be comprehended by automatic processing alone (Graf and Landwehr 2015, 2017). Furthermore, it can be predicted that the processing of metaphoric ads is difficult in the beginning but becomes easy once the metaphoric riddle has been solved.

Third, concerning the question when metaphoric advertising increases appreciation, the MAP again makes testable predictions for the underlying mechanisms that may explain the commonly observed inverted u-shape relationship between metaphoric complexity and ad appreciation (e.g., van Mulken et al. 2010, 2014). In particular, the pathways leading to the three distinct outcomes of the MAP (see Fig. 1) exactly specify the causal sequence of the processes that are presumably responsible for producing an inverted $\mathrm{u}$-shape pattern. Testing the existence of these causal pathways by mediation analyses or structural equation modelling remains an important task for future research. Importantly, one key prediction of the MAP is that disfluency reduction is the key psychological mechanism that contributes to the effectiveness of metaphoric advertising. Disfluency reduction has been proposed in the field of aesthetic appreciation (Graf and Landwehr 2015) and examined in studies on product design (Graf and Landwehr 2017). However, it has not been empirically examined in the field of advertising. Moreover, although disfluency reduction is by definition a dynamically changing construct, it was only examined using static self-report measures. Thus, we suggest examining disfluency reduction using dynamic measures of fluency (e.g., neurophysiological measures) in the domain of metaphoric versus straightforward advertising.

Fourth, the MAP also offers new perspectives on why metaphoric advertising triggers specific inferences about brand personality characteristics (Ang and Lim 2006) and why metaphoric advertising is able to trigger multiple cognitive inferences simultaneously (McQuarrie and Philipps 2005; Zaltman 2016). In particular, considering the sudden increase in processing fluency as the core mechanism involved in the processing of metaphoric ads suggests that known inferential consequences of the experience of fluency are also likely to occur for metaphoric ads. More specifically, the fluency literature suggests that the experience of fluency triggers inferences about truth (e.g., Reber and Schwarz 1999; Graf et al. 2018), trustworthiness (Sofer et al. 2015), safety (Dohle and Siegrist 2014; Song and Schwarz 2009), and ordinariness (Pocheptsova et al. 2010). For future research it would, thus, be interesting to examine whether these specific inferences are more likely to occur for metaphoric advertising than other inferences not connected to processing fluency.

Fifth and finally, the different moderators of the effectiveness of metaphoric advertising summarized in Table 2 (i.e., need for cognition, level of education, age, hemispheric processing, and presence of an explanatory headline) can, according to the MAP, all be understood as factors that modulate the 
fluency of processing a metaphoric ad. Thus, the MAP would predict that fluency could constitute an overarching theoretical concept to systematize the moderating conditions of metaphoric advertising. Thus, for future research it would be interesting to examine whether these moderators influence the amount of fluency experienced or the link between fluency and appreciation. Moreover, the quest for additional moderators by future research could be based on other known moderators of processing fluency such as exposure (Landwehr et al. 2013) or expertise (Reber et al. 2004).

\section{General discussion}

In this article, we presented a literature review on metaphoric and straightforward advertising and articulated important research gaps. Based on this overview, we propose the Metaphoric Advertising Processing Model (MAP) - a novel conceptual perspective on metaphoric and straightforward advertising. The MAP extends former models such as the Remote Conveyor Model (Rossiter and Bellman 2005; Rossiter and Percy 1997) by integrating concepts from schema congruity theory, processing fluency theory, and structuremapping theory to achieve a process-oriented understanding of metaphoric advertising. Thereby, the MAP offers the following three main contributions to the literature:

i. It juxtaposes metaphoric and straightforward advertising from a consumer's perspective. In accordance with the literature, we define metaphoric advertising as a complex, figurative, and indirect way of communication. A metaphor infuses an ad with surplus meaning, which unfolds through resolving the incongruence between visual ad elements. In contrast, straightforward advertising communicates in an illustrative and descriptive manner. The visual ad elements are congruent and do not contain additional hidden layers of meaning.

ii. Based on this definition, our framework distinguishes between distinct paths of consumer processing. We propose that different degrees of incongruity between ad elements produce different degrees of processing fluency. We suggest that metaphoric advertising is initially processed less fluently than straightforward advertising. If consumers can detect the surplus meaning of a metaphoric ad, they can successfully reduce feelings of disfluency. More precisely, we suggest that a sudden change in processing fluency (i.e., abrupt disfluency reduction) caused by an aha insight triggers ad appreciation and liking.

iii. We emphasize that the positive outcomes of metaphoric advertising, triggered by a moderate level of incongruity, disfluency reduction, and the aha moment, occur only if the consumer detects the underlying meaning of the advertising message. This hidden meaning can be uncovered by conceptually relating the visual ad elements or by applying conventional knowledge. However, if the consumer fails to uncover the underlying meaning, metaphoric advertising may be frustrating and produces negative effects.

In addition to the development of the MAP, the current article also offers a comprehensive review of the current literature on metaphoric advertising and identifies nine important research gaps that are summarized in Table 2. Importantly, the psychological processes proposed by the MAP make specific, testable predictions for future research in order to close these gaps. Accordingly, an empirical examination of these predictions would substantially improve our understanding of metaphoric advertising.

\section{Potential links to other research domains}

Beyond the concrete implications for future research on metaphoric advertising, the predictions made by the MAP could also be extended to research areas not yet connected to the field of metaphoric advertising. In the present section, we outline three exemplary fields of research that could benefit from considering the insights described in the present article to achieve an improved understanding of their respective object of knowledge.

First, an influential model for studying the effect of advertising is evaluative conditioning (EC). A recent meta-analysis of this field (Hofmann et al. 2010) suggests that EC effects tend to be stronger when consumers become aware of the contingent pairing of conditioned stimulus (i.e., the product or the brand in an advertisement) and unconditioned stimulus (i.e., a highly emotional stimulus in an advertisement) because of effortful processing. Moreover, the experience of fluency caused by conditioning has been shown to enhance positive EC effects (Landwehr et al. 2017). Since metaphoric advertising increases processing efforts and triggers a sudden increase in processing fluency, the current literature on EC would suggest that using metaphoric ads in studies on EC should produce especially strong EC effects. Hence, we suggest to examine whether metaphoric stimuli are indeed an important moderator for EC effects that should be considered by research on EC phenomena.

Second, an important theoretical framework for an improved understanding of consumers' product evaluation and choice is the Construal Level-Theory of Psychological Distance (Trope and Liberman 2010). Because of the increased usage of computers and the Internet, marketplace behaviors change and products are increasingly digitalized - and thus intangible. We purchase books online rather than in bookshops; we listen to digital music files rather than vinyl records; we store photos on our tablets rather than printing them. Because such intangible products are remote from consumers' 
direct experience, they are processed on a high construal level and consumers' mental representation is abstract. Recent research applying construal level-theory to consumers' choice confidence has shown that confidence can be increased when construal level is low (i.e., concrete) and consumers experience processing fluency (Tsai and McGill 2011). Because prior research on metaphoric advertising suggests that metaphors make abstract concepts more concrete (Burgers et al. 2015) and the MAP suggests that resolving the puzzle of metaphoric advertising triggers fluency, there seems to be an interesting link between these streams of research. Hence, studying the effects of metaphoric advertising from a construal level perspective could enrich the corresponding literature. In addition, empirically investigating whether metaphoric advertising is in general more suitable for intangible product characteristics or services would also provide important insights for this related field of research.

Third, in order to improve consumers' decision making with respect to long term goals such as health and well-being, recent research emphasizes the importance of consumers' skills and competencies to make better decisions, which has been called boosting (Hertwig and Grüne-Yanoff 2017). An essential aspect of boosting is that consumers fully understand why and how they can improve their consumption behavior. Because the MAP predicts that metaphoric advertising is able to trigger aha insights, it could be a beneficial instrument for public policy makers to increase consumers' understanding of the need for behavioral change and consumers' confidence in their ability to learn new behavioral patterns. Hence, examining consumers' empowerment by means of boosting could directly benefit from considering the proposed mechanisms underlying the processing of metaphoric advertising.

\section{Implications}

Our paper aims to supply researchers and practitioners with a structured overview of metaphors in advertising and to provide guidance for designing successful metaphoric advertising campaigns. One field of application that may become particularly relevant to metaphoric advertising is the rapidly evolving area of individualized online advertising. Online advertising allows advertisers to customize their advertisements for individual consumers. The implications of this opportunity for metaphoric advertising are twofold. First, the advertiser can adjust the difficulty of resolving the incongruity between the visual ad elements for different groups of consumers such that a maximum number of consumers will experience an aha moment that improves their attitude toward the ad. Second, if individualized metaphoric ad elements are used, the fit between the metaphoric message and the desired self-concepts of the consumers can be increased such that the symbolic associations triggered by the metaphoric ad can help consumers to express their selves and their identities (see Belk 1988; Levy 1959).

Another important implication of our metaphoric advertising framework concerns the measurement of advertising effectiveness. Current efforts to quantify the success of advertising typically focus on quantitative input factors (e.g., advertising expenses). By highlighting the importance of metaphoric advertising, we emphasize that qualitative aspects (e.g., advertising content) are crucial for a more comprehensive understanding of advertising effectiveness.

In sum, we hope that the MAP provides a helpful conceptual "map" that guides researchers and practitioners through the rich existing literature on metaphoric advertising. Moreover, we hope that the MAP points to important undiscovered territories in the realm of metaphoric advertising that will eventually inspire researchers to find promising avenues for future research.

Acknowledgments This research did not receive a specific grant from funding agencies in the public, commercial, or not-for-profit sectors. We would like to thank the editor and three anonymous reviewers for very helpful and constructive comments during the review process. We also thank Daniel Wentzel, Laura K. M. Graf, Simone Dohle, and Rolf Reber for providing very helpful feedback on an earlier draft of this article.

Open Access This article is distributed under the terms of the Creative Commons Attribution 4.0 International License (http:// creativecommons.org/licenses/by/4.0/), which permits unrestricted use, distribution, and reproduction in any medium, provided you give appropriate credit to the original author(s) and the source, provide a link to the Creative Commons license, and indicate if changes were made.

Publisher's note Springer Nature remains neutral with regard to jurisdictional claims in published maps and institutional affiliations.

\section{References}

Aggarwal, P., \& McGill, A. L. (2007). Is that car smiling at me? Schema congruity as a basis for evaluating anthropomorphized products. Journal of Consumer Research, 34(4), 468-479.

Aguirre-Rodriguez, A. (2014). Cultural factors that impact brand personification strategy effectiveness. Psychology and Marketing, 31(1), 70-83. https://doi.org/10.1002/mar.20676.

Alden, D. L., Steenkamp, J.-B. E. M., \& Batra, R. (1999). Brand positioning through advertising in Asia, North America, and Europe: The role of global consumer culture. Journal of Marketing, 63(1), 75-87. https://doi.org/10.2307/1252002.

Ang, S. H., \& Lim, E. A. C. (2006). The influence of metaphors and product type on brand personality perceptions and attitudes. Journal of Advertising, 35(2), 39-53. https://doi.org/10.1080/ 00913367.2006 .10639226$.

Belk, R. W. (1988). Possessions and the extended self. Journal of Consumer Research, 15(2), 139-168. https://doi.org/10.1086/ 209154. 
Bergkvist, L., Eiderbäck, D., \& Palombo, M. (2012). The brand communication effects of using a headline to prompt the key benefit in ads with pictorial metaphors. Journal of Advertising, 41(2), 67-76.

Berlyne, D. E. (1960). Conflict, arousal, and curiosity. New York: McGraw-Hill.

Brown, S. P., \& Stayman, D. M. (1992). Antecedents and consequences of attitude toward the ad: A meta-analysis. Journal of Consumer Research, 19(1), 34-51.

Burgers, C., Konijn, E. A., Steen, G. J., \& Iepsma, M. A. R. (2015). Making ads less complex, yet more creative and persuasive: The effects of conventional metaphors and irony in print advertising. International Journal of Advertising, 34(3), 515-532. https://doi. org/10.1080/02650487.2014.996200.

Callow, M. A., \& Schiffman, L. G. (1999). A visual Esperanto? The pictorial metaphor in global advertising. European Advances in Consumer Research, 4, 17-20.

Chang, C.-T., \& Yen, C.-T. (2013). Missing ingredients in metaphor advertising: The right formula of metaphor type, product type, and need for cognition. Journal of Advertising, 42(1), 80-94. https:// doi.org/10.1080/00913367.2012.749090.

Cho, H., \& Schwarz, N. (2006). If I don't understand it, it must be new: Processing fluency and perceived product innovativeness. In C. Pechmann \& L. P. Price (Eds.), Advances in consumer research (Vol. 33). Duluth: Association for Consumer Research.

Cian, L., Krishna, A., \& Schwarz, N. (2015). Positioning rationality and emotion: Rationality is up and emotion is down. Journal of Consumer Research, 42(4), 632-651. https://doi.org/10.1093/jcr/ ucv046.

Corbett, E. P. J. (1990). Classical rhetoric for the modern student. New York: Oxford University Press.

Delbaere, M., McQuarrie, E. F., \& Phillips, B. J. (2011). Personification in advertising. Journal of Advertising, 40(1), 121-130. https://doi. org/10.2753/JOA0091-3367400108.

DeRosia, E. D. (2008). The effectiveness of nonverbal symbolic signs and metaphors in advertisements: An experimental inquiry. Psychology and Marketing, 25(3), 298-316. https://doi.org/10. 1002/mar.20210.

Dohle, S., \& Siegrist, M. (2014). Fluency of pharmaceutical drug names predicts perceived hazardousness, assumed side effects and willingness to buy. Journal of Health Psychology, 19(10), 1241-1249. https://doi.org/10.1177/1359105313488974.

Dondis, D. A. (1973). A primer of visual literacy. Cambridge: MIT Press.

Fox, G. L., Rinaldo, S. B., \& Amant, K. S. (2015). The effects of rhetorical figures and cognitive load in word-of-mouth communications. Psychology and Marketing, 32(10), 1017-1030. https://doi.org/10. 1002/mar.20839.

Gentner, D. (1983). Structure-mapping: A theoretical framework for analogy. Cognitive Science, 7(2), 155-170. https://doi.org/10.1207/ s15516709 $\operatorname{cog} 0702$ 3.

Gentner, D., Bowdle, B. F., Wolff, P., \& Boronat, C. (2001). Metaphor is like analogy. In D. Gentner, K. J. Holyoak, \& B. N. Kokinov (Eds.), The analogical mind: Perspectives from cognitive science. Cambridge: MIT Press.

Gibbs, R. W., Jr. (2000). Making good psychology out of blending theory. Cognitive Linguistics, 11(3-4), 347-358.

Gkiouzepas, L., \& Hogg, M. K. (2011). Articulating a new framework for visual metaphors in advertising. Journal of Advertising, 40(1), 103120. https://doi.org/10.2753/JOA0091-3367400107.

Graf, L. K. M., \& Landwehr, J. R. (2015). A dual-process perspective on fluency-based aesthetics: The pleasure-interest model of aesthetic liking. Personality and Social Psychology Review, 19(4), 395-410. https://doi.org/10.1177/1088868315574978.

Graf, L. K. M., \& Landwehr, J. R. (2017). Aesthetic pleasure versus aesthetic interest: The two routes to aesthetic liking. Frontiers in Psychology, 8(15). https://doi.org/10.3389/fpsyg.2017.00015.
Graf, L. K. M., Mayer, S., \& Landwehr, J. R. (2018). Measuring processing fluency: One versus five items. Journal of Consumer Psychology, 28(3), 393-411. https://doi.org/10.1002/jcpy.1021.

Hawkins, D. I. (1973). Model of symbolic communication. Journal of Advertising Research, 13(3), 33-38.

Hertwig, R., \& Grüne-Yanoff, T. (2017). Nudging and boosting: Steering or empowering good decisions. Perspectives on Psychological Science, 12(6), 973-986. https://doi.org/10.1177/ 1745691617702496 .

Hofmann, W., De Houwer, J., Perugini, M., Baeyens, F., \& Crombez, G. (2010). Evaluative conditioning in humans: A meta-analysis. Psychological Bulletin, 136(3), 390-421. https://doi.org/10.1037/ a0018916.

Homer, P. M. (1990). The mediating role of attitude toward the ad: Some additional evidence. Journal of Marketing Research, 27(1), 78-86.

Kim, J., Baek, Y., \& Choi, Y. H. (2012). The structural effects of metaphor-elicited cognitive and affective elaboration levels on attitude toward the ad. Journal of Advertising, 41(2), 77-96. https://doi. org/10.2753/JOA0091-3367410206.

Lagerwerf, L., \& Meijers, A. (2008). Openness in metaphorical and straightforward advertisements: Appreciation effects. Journal of Advertising, 37(2), 19-30. https://doi.org/10.2753/JOA00913367370202 .

Lakoff, G., \& Johnson, M. (1980). The metaphorical structure of the human conceptual system. Cognitive Science, 4(2), 195-208.

Lakoff, G., \& Johnson, M. (2003). Metaphors we live by. Chicago: The University of Chicago Press.

Landwehr, J. R., McGill, A. L., \& Herrmann, A. (2011). It's got the look: The effect of friendly and aggressive "facial" expressions on product liking and sales. Journal of Marketing, 75(3), 132-146.

Landwehr, J. R., Wentzel, D., \& Herrmann, A. (2013). Product design for the long run: Consumer responses to typical and atypical designs at different stages of exposure. Journal of Marketing, 77(5), 92-107.

Landwehr, J. R., Golla, B., \& Reber, R. (2017). Processing fluency: An inevitable side effect of evaluative conditioning. Journal of Experimental Social Psychology, 70, 124-128. https://doi.org/10. 1016/j.jesp.2017.01.004.

Levy, S. J. (1959). Symbols for sale. Harvard Business Review, 37(4), $117-124$

MacKenzie, S. B., Lutz, R. J., \& Belch, G. E. (1986). The role of attitude toward the ad as a mediator of advertising effectiveness: A test of competing explanations. Journal of Marketing Research, 23(2), 130-143.

Mandler, G. (1982). The structure of value: Accounting for taste. In M. S. Clark \& S. T. Fiske (Eds.), Affect and cognition: The 17th annual Carnegie symposium (pp. 3-36). Hillsdale: Lawrence Erlbaum Associates.

McQuarrie, E. F., \& Mick, D. G. (1996). Figures of rhetoric in advertising language. Journal of Consumer Research, 22(4), 424-438. https:// doi.org/10.1086/209459.

McQuarrie, E. F., \& Mick, D. G. (1999). Visual rhetoric in advertising: Text-interpretive, experimental, and reader-response analyses. Journal of Consumer Research, 26(1), 37-54. https://doi.org/10. 1086/209549.

McQuarrie, E. F., \& Philipps, B. J. (2005). Indirect persuasion in advertising: How consumers process metaphors presented in pictures and words. Journal of Advertising, 34(2), 7-20.

Meyers-Levy, J., \& Tybout, A. M. (1989). Schema congruity as a basis for product evaluation. Journal of Consumer Research, 16(1), 39 54. https://doi.org/10.1086/209192.

Mick, D. G. (1992). Levels of subjective comprehension in advertising processing and their relations to ad perceptions, attitudes, and memory. Journal of Consumer Research, 18(4), 411-424. https://doi.org/ $10.1086 / 209270$ 
Mitchell, A. A., \& Olson, J. C. (1981). Are product attribute beliefs the only mediator of advertising effects on brand attitude? Journal of Marketing Research, 18(3), 318-332.

Mohanty, P. (, \& Ratneshwar, S. (2015). Did you get it? Factors influencing subjective comprehension of visual metaphors in advertising. Journal of Advertising, 44(3), 232-242. doi:https://doi.org/10. 1080/00913367.2014.967424.

Morgan, S. E., \& Reichert, T. (1999). The message is in the metaphor: Assessing the comprehension of metaphors in advertisements. Journal of Advertising, 28(4), 1-12.

Moriarty, S. E. (1987). A content analysis of visuals used in print media advertising. Journalism Quarterly, 64(2-3), 550-554. https://doi. org/10.1177/107769908706400238.

Motyka, S., Suri, R., Grewal, D., \& Kohli, C. (2016). Disfluent vs. fluent price offers: Paradoxical role of processing disfluency. Journal of the Academy of Marketing Science, 44(5), 627-638. https://doi.org/ 10.1007/s11747-015-0459-0.

Muth, C., \& Carbon, C. C. (2013). The aesthetic Aha: On the pleasure of having insights into gestalt. Acta Psychologica, 144(1), 25-30. https://doi.org/10.1016/j.actpsy.2013.05.001.

Pawlowski, D. R., Badzinski, D. M., \& Mitchell, N. (1998). Effects of metaphors on children's comprehension and perception of print advertisements. Journal of Advertising, 27(2), 83-98.

Pezzo, M. V. (2003). Surprise, defence, or making sense: What removes hindsight bias? Memory, 11(4/5), 421-441. https://doi.org/10.1080/ 09658210244000603.

Phillips, B. J. (1997). Thinking into it: Consumer interpretation of complex advertising images. Journal of Advertising, 26(2), 77-87. https://doi.org/10.1080/00913367.1997.10673524.

Phillips, B. J. (2000). The impact of verbal anchoring on consumer response to image ads. Journal of Advertising, 29(1), 15-24.

Phillips, B. J., \& McQuarrie, E. F. (2004). Beyond visual metaphor: A new typology of visual rhetoric in advertising. Marketing Theory, 4(1-2), 113-136. https://doi.org/10.1177/1470593104044089.

Pocheptsova, A., Labroo, A. A., \& Dhar, R. (2010). Making products feel special: When metacognitive difficulty enhances evaluation. Journal of Marketing Research, 47(6), 1059-1069.

Randazzo, S. (2006). Subaru: The emotional myths behind the brand's growth. Journal of Advertising Research, 46(1), 11-17. https://doi. org/10.2501/S002184990606003X.

Reber, R., \& Schwarz, N. (1999). Effects of perceptual fluency on judgments of truth. Consciousness and Cognition, 8(3), 338-342.

Reber, R., Schwarz, N., \& Winkielman, P. (2004). Processing fluency and aesthetic pleasure: Is beauty in the perceiver's processing experience? Personality and Social Psychology Review, 8(4), 364-382. https://doi.org/10.1207/s15327957pspr0804_3.

Rossiter, J. R. (2008). Defining the necessary components of creative, effective ads. Journal of Advertising, 37(4), 139-144.

Rossiter, J. R., \& Bellman, S. (2005). Marketing communications: Theory and applications. Frenchs Forest: Pearson education Australia.
Rossiter, J. R., \& Percy, L. (1997). Advertising communications and promotion management. New York: McGraw-Hill.

Scott, L. M. (1994). Images in advertising: The need for a theory of visual rhetoric. Journal of Consumer Research, 21(2), 252-273. https:// doi.org/10.1086/209396.

Shannon, C. E., \& Weaver, W. (1949). The mathematical theory of communication. Urbana: University of Illinois Press.

Sofer, C., Dotsch, R., Wigboldus, D. H. J., \& Todorov, A. (2015). What is typical is good: The influence of face typicality on perceived trustworthiness. Psychological Science, 26(1), 39-47. https://doi.org/10. 1177/0956797614554955.

Song, H., \& Schwarz, N. (2009). If it's difficulty to pronounce, it must be risky. Psychological Science, 20(2), 135-138.

Toncar, M., \& Munch, J. (2001). Consumer responses to tropes in print advertising. Journal of Advertising, 30(1), 55-65. https://doi.org/10. 1080/00913367.2001.10673631.

Topolinski, S., \& Reber, R. (2010). Gaining insight into the 'Aha' experience. Current Directions in Psychological Science, 19(6), 402405. https://doi.org/10.1177/0963721410388803.

Trope, Y., \& Liberman, N. (2010). Construal-level theory of psychological distance. Psychological Review, 117(2), 440-463. https://doi. org/10.1037/a0018963.

Tsai, C. I., \& McGill, A. L. (2011). No pain, no gain? How fluency and construal level affect consumer confidence. Journal of Consumer Research, 37(5), 807-821. https://doi.org/10.1086/655855.

van Mulken, M., Le Pair, R., \& Forceville, C. (2010). The impact of perceived complexity, deviation, and comprehension on the appreciation of visual metaphor in advertising across three European countries. Journal of Pragmatics, 42(12), 3418-3430.

van Mulken, M., van Hooft, A., \& Nederstigt, U. (2014). Finding the tipping point: Visual metaphor and conceptual complexity in advertising. Journal of Advertising, 43(4), 333-343. https://doi.org/10. 1080/00913367.2014.92028.

Vance, K., \& Virtue, S. (2011). Metaphoric advertisement comprehension: The role of the cerebral hemispheres. Journal of Consumer Behaviour, 10(1), 41-50. https://doi.org/10.1002/cb.345.

Wänke, M., \& Hansen, J. (2015). Relative processing fluency. Current Directions in Psychological Science, 24(3), 195-199. https://doi. org/10.1177/0963721414561766.

Zaltman, G. (2016). Marketing's forthcoming age of imagination. AMS Review, 6(3-4), 99-115. https://doi.org/10.1007/s13162016-0082-3

Zaltman, G., \& Coulter, R. H. (1995). Seeing the voice of the customer: Metaphor-based advertising research. Journal of Advertising Research, 35(4), 35-51. 